\title{
On the application of the multistage laplace Adomian decomposition method to the chaotic Chen system
}

\author{
Saheed O. Ajibola, Olusola T. Kolebaje*, Samuel O. Sedara \\ Department of Mathematics, National Open University of Nigeria. \\ Department of Physics, Adeyemi College of Education, Ondo, Nigeria. \\ Department of Physics, University of Ibadan, Nigeria. \\ *Corresponding author E-mail: olusolakolebaje2008@gmail.com
}

\begin{abstract}
In this paper, Laplace Adomian Decomposition Method (LADM) and the Multistage Laplace Adomian Decomposition Method (MLADM) were applied to obtain solutions to the Chen system for the non-chaotic and chaotic case. The study shows that the LADM only gives reliable results for $\mathrm{t}<<1$. Comparison between the MLADM and the classical fourthorder Runge-Kutta (RK4) solutions shows that the MLADM performs well with high accuracy. The study shows that MLADM is a powerful and promising tool for solving nonlinear systems of ODEs of chaotic and non-chaotic nature.
\end{abstract}

Keywords: Chaos, Chen system, Dynamical systems, Laplace Adomian Decomposition method, Multi-staging.

\section{Introduction}

Chaos theory studies the behaviour of dynamical systems that are highly sensitive to initial conditions. Chaos theory is applied in many scientific disciplines, including: physics, geology, mathematics, biology, computer science, economics [1-2], engineering, finance, meteorology, philosophy and population dynamics.

The Chen system developed by Chen and Ueta in 1999 is a set of coupled ordinary differential equation with quadratic nonlinearities and is defined by [3]:

$$
\begin{aligned}
& \frac{d x}{d t}=a(y-x) \\
& \frac{d y}{d t}=(c-a) x-x z+c y \\
& \frac{d z}{d t}=x y-b z
\end{aligned}
$$

Where $x, y, z$ are the dependent variables and $a, b, c$ are positive real numbers. The Chen system has chaotic and non chaotic behaviour for different parameter values. Bifurcation studies [4-6] have shown that the Chen system exhibits chaotic and non-chaotic behaviour for the parameter sets $(a, b, c)=(35,3,28)$ and $(a, b, c)=(35,12,28)$ respectively. Finding accurate and efficient methods for solving chaotic systems such as the Chen system has been an active area of research in recent times [7-10].

The concept of Laplace Adomian decomposition method (LADM) was first introduced by Khuri [11-12]. LADM is a promising method and has been applied in solving various differential equations [13-15]. However, LADM has some drawbacks like most semi-analytic schemes. By using the LADM, we obtain a series solution, actually a truncated series solution. This series solution does not exhibit the real behaviours of the problem but gives a good approximation to the true solution in a very small region. Since the LADM has a very small convergence region, a multi-staging technique known as the Multistage Laplace Adomian Decomposition Method (MLADM) is proposed.

The motivation of this paper is to apply the LADM and MLADM to the Chen system for both chaotic and non-chaotic scenarios and test the accuracy of the method with the well known fourth order Runge-Kutta method. The computations in this paper were carried out with the computer algebraic system MATHEMATICA. 


\section{Methodology}

\subsection{Laplace Adomian Decomposition Method (LADM)}

In this section, we present a Laplace Adomian decomposition method for solving a differential equation written in operator form as:

$L_{t} u+R(u)+N(u)=g$

With initial condition

$u(x, 0)=f(x)$

Where $L_{t}$ is a first-order differential operator, $R$ is a linear operator, $N$ is a non-linear operator and $g$ is the source term. We start by applying Laplace transform to both sides of equation (2) and then apply the initial condition (3).

$\mathcal{L}\left[L_{t} u\right]+\mathcal{L}[R(u)]+\mathcal{L}[N(u)]=\mathcal{L}[g]$

$s \mathcal{L}[u]-f(x)=\mathcal{L}[g]-\mathcal{L}[R(u)]-\mathcal{L}[N(u)]$

$\mathcal{L}[u]=\frac{f(x)}{s}+\frac{\mathcal{L}[g]}{s}-\frac{\mathcal{L}[R(u)]}{s}-\frac{\mathcal{L}[N(u)]}{s}$

The LADM defines the solution $u(x, t)$ as an infinite series of the form

$u(x, t)=\sum_{n=0}^{\infty} u_{n}$

The non-linear term is expressed in terms of the Adomian polynomials given by [16]:

$N(u)=\sum_{n=0}^{\infty} A_{n}$

$A_{n}=\frac{1}{n !}\left[\frac{d^{n}}{d \lambda^{n}}\left[N \sum_{i=0}^{\infty} \lambda^{i} u_{i}\right]\right]$

Substituting (6) and (7) into (4) gives:

$\mathcal{L}\left[\sum_{n=0}^{\infty} u_{n}\right]=\frac{f(x)}{s}+\frac{\mathcal{L}[g]}{s}-\frac{\mathcal{L}[R(u)]}{s}-\frac{\mathcal{L}\left[\sum_{n=0}^{\infty} A_{n}\right]}{s}$

From (9), we can define the following recursive formula:

$\mathcal{L}\left[u_{0}\right]=\frac{f(x)}{s}+\frac{\mathcal{L}[g]}{s}$

$\mathcal{L}\left[u_{n+1}\right]=-\frac{\mathcal{L}[R(u)]}{s}-\frac{\mathcal{L}\left[A_{n}\right]}{s}$

Applying the inverse Laplace transform to both sides of (10) and (11) we obtain $u_{n}(n \geq 0)$ which is then substituted into (6).

\subsection{Multistage Laplace Adomian Decomposition Method (MLADM)}

An efficient way of ensuring the validity of solutions to differential equations for large $t(t \gg 0)$ is by multi-staging the solution procedure to be employed. Let $[0, T]$ be the interval over which the solutions to the differential equation (1) is to be determined. The solution interval $[0, T]$ is divided into $N$ subintervals $(n=1,2, \ldots \ldots \ldots, N)$ of equal step size given by $h=T / N$ with the interval end points $t_{n}=n h$.

Initially, the LADM scheme is applied to obtain the approximate solutions of $x, y$ and $z$ of $(1)$ over the interval $\left[0, t_{1}\right]$ by using the initial condition $x(0), y(0)$ and $z(0)$ respectively. For obtaining the approximate solution of (1) over the next interval $\left[t_{1}, t_{2}\right]$, we take $x\left(t_{1}\right), y\left(t_{1}\right)$ and $z\left(t_{1}\right)$ as the initial condition. Generally the scheme is repeated for any $n$ with the right endpoints $x\left(t_{m-1}\right), y\left(t_{m-1}\right)$ and $z\left(t_{m-1}\right)$ at the previous interval being used as the initial condition for the interval $\left[t_{m-1}, t_{m}\right]$. 


\section{Application}

In this section, we apply the Laplace Adomian decomposition method to the Chen system (1). The fundamental operation of Laplace Adomian decomposition method is applied to the Chen system is given below:

$\mathcal{L}\left[\frac{\mathrm{dx}}{\mathrm{dt}}\right]=a \mathcal{L}[\mathrm{y}]-a \mathcal{L}[\mathrm{x}]$

$\mathcal{L}\left[\frac{\mathrm{dy}}{\mathrm{dt}}\right]=\mathrm{c} \mathcal{L}[\mathrm{x}]-\mathrm{a} \mathcal{L}[\mathrm{x}]-\mathcal{L}[\mathrm{xz}]+\mathrm{c} \mathcal{L}[\mathrm{y}]$

$\mathcal{L}\left[\frac{\mathrm{dz}}{\mathrm{dt}}\right]=\mathcal{L}[\mathrm{xy}]-b \mathcal{L}[\mathrm{z}]$

$s \mathcal{L}[\mathrm{x}]-x(0)=a \mathcal{L}[\mathrm{y}]-a \mathcal{L}[\mathrm{x}]$

$s \mathcal{L}[\mathrm{y}]-y(0)=\mathrm{c} \mathcal{L}[\mathrm{x}]-\mathrm{a} \mathcal{L}[\mathrm{x}]-\mathcal{L}[\mathrm{xz}]+\mathrm{c} \mathcal{L}[\mathrm{y}]$

$s \mathcal{L}[\mathrm{z}]-z(0)=\mathcal{L}[\mathrm{xy}]-b \mathcal{L}[\mathrm{z}]$

$\mathcal{L}[\mathrm{x}]=\frac{x(0)}{s}+\frac{a}{s} \mathcal{L}[\mathrm{y}]-\frac{a}{s} \mathcal{L}[\mathrm{x}]$

$\mathcal{L}[\mathrm{y}]=\frac{y(0)}{s}+\frac{\mathrm{c}}{\mathrm{s}} \mathcal{L}[\mathrm{x}]-\frac{\mathrm{a}}{\mathrm{s}} \mathcal{L}[\mathrm{x}]-\frac{1}{\mathrm{~s}} \mathcal{L}[\mathrm{xz}]+\frac{\mathrm{c}}{\mathrm{s}} \mathcal{L}[\mathrm{y}]$

$\mathcal{L}[\mathrm{z}]=\frac{z(0)}{\mathrm{s}}+\frac{1}{\mathrm{~s}} \mathcal{L}[\mathrm{xy}]-\frac{\mathrm{b}}{\mathrm{s}} \mathcal{L}[\mathrm{z}]$

The solution of the Chen system takes the form

$x(t)=\sum_{n}^{\infty} X_{n} \quad y(t)=\sum_{n}^{\infty} Y_{n} \quad z(t)=\sum_{n}^{\infty} Z_{n}$

The non-linear terms are expressed as:

$\mathrm{xy}=\sum_{n}^{\infty} F_{n} \quad \mathrm{xz}=\sum_{n}^{\infty} G_{n}$

Then (13) can be written as a recursive formula as:

$$
\begin{aligned}
& \mathcal{L}\left[\sum X_{n}\right]=\frac{x(0)}{s}+\frac{a}{s} \mathcal{L}\left[\sum Y_{n}\right]-\frac{a}{s} \mathcal{L}\left[\sum X_{n}\right] \\
& \mathcal{L}\left[\sum Y_{n}\right]=\frac{y(0)}{s}+\frac{\mathrm{c}}{\mathrm{s}} \mathcal{L}\left[\sum X_{n}\right]-\frac{\mathrm{a}}{\mathrm{s}} \mathcal{L}\left[\sum X_{n}\right] \\
& -\frac{1}{\mathrm{~s}} \mathcal{L}\left[\sum G_{n}\right]+\frac{\mathrm{c}}{\mathrm{s}} \mathcal{L}\left[\sum Y_{n}\right] \\
& \mathcal{L}\left[\sum Z_{n}\right]=\frac{z(0)}{\mathrm{s}}+\frac{1}{\mathrm{~s}} \mathcal{L}\left[\sum F_{n}\right]-\frac{\mathrm{b}}{\mathrm{s}} \mathcal{L}\left[\sum Z_{n}\right]
\end{aligned}
$$

From (14) we have:

$$
\begin{array}{lll}
\mathcal{L}\left[X_{0}\right]=\frac{x(0)}{s} & \mathcal{L}\left[Y_{0}\right]=\frac{y(0)}{s} & \mathcal{L}\left[Z_{0}\right]=\frac{z(0)}{\mathrm{s}} \\
X_{0}=\mathcal{L}^{-1}\left[\frac{x(0)}{s}\right] & Y_{0}=\mathcal{L}^{-1}\left[\frac{y(0)}{s}\right] & Z_{0}=\mathcal{L}^{-1}\left[\frac{z(0)}{s}\right]
\end{array}
$$




$$
\begin{aligned}
& \mathcal{L}\left[X_{n+1}\right]=\frac{a}{s} \mathcal{L}\left[Y_{n}\right]-\frac{a}{s} \mathcal{L}\left[X_{n}\right] \\
& \mathcal{L}\left[Y_{n+1}\right]=\frac{\mathrm{c}}{\mathrm{s}} \mathcal{L}\left[X_{n}\right]-\frac{\mathrm{a}}{\mathrm{s}} \mathcal{L}\left[X_{n}\right]-\frac{1}{\mathrm{~s}} \mathcal{L}\left[G_{n}\right]+\frac{\mathrm{c}}{\mathrm{s}} \mathcal{L}\left[Y_{n}\right] \\
& \mathcal{L}\left[Z_{n+1}\right]=\frac{1}{\mathrm{~s}} \mathcal{L}\left[F_{n}\right]-\frac{\mathrm{b}}{\mathrm{s}} \mathcal{L}\left[Z_{n}\right] \\
& X_{n+1}=\mathcal{L}^{-1}\left[\frac{\mathrm{a}}{\mathrm{s}} \mathcal{L}\left[Y_{n}\right]-\frac{\mathrm{a}}{\mathrm{s}} \mathcal{L}\left[X_{n}\right]\right] \\
& Y_{n+1}=\mathcal{L}^{-1}\left[\frac{\mathrm{c}}{\mathrm{s}} \mathcal{L}\left[X_{n}\right]-\frac{\mathrm{a}}{\mathrm{s}} \mathcal{L}\left[X_{n}\right]-\frac{1}{\mathrm{~s}} \mathcal{L}\left[G_{n}\right]+\frac{\mathrm{c}}{\mathrm{s}} \mathcal{L}\left[Y_{n}\right]\right] \\
& Z_{n+1}=\mathcal{L}^{-1}\left[\frac{1}{\mathrm{~s}} \mathcal{L}\left[F_{n}\right]-\frac{\mathrm{b}}{\mathrm{s}} \mathcal{L}\left[Z_{n}\right]\right]
\end{aligned}
$$

The system is solved with the initial condition $x(0)=-10, y(0)=0$ and $z(0)=37$. For $b=3$, we have a chaotic system and $b=12$ correspond to a non-chaotic system. The recursive relations (15) and (17) are evaluated with the aid of Mathematica to obtain the solution up to a 21 terms approximation for the time range $[0,30]$ with a time step size 0.01 . MLADM is implemented by dividing the solution interval $[0,30]$ into 300 subintervals $(n=1,2, \ldots \ldots \ldots, 300)$ of equal step size given by $h=0.1$

\section{$4 \quad$ Results and discussion}

The chaotic case of the Chen system was solved using the LADM and MLADM implemented on Mathematica, the 21 terms approximate LADM solution was obtained as

$$
\begin{aligned}
& x=-10+350 t+1575 t^{2}-\frac{128450}{3} t^{3}+\frac{2217525}{4} t^{4}+\frac{11186560}{24} t^{5}-\frac{7540234456}{24} t^{6}-\frac{4384159955}{18} t^{7}+\cdots \\
& y=440 t-2095 t^{2}-\frac{109445}{3} t^{3}+\frac{7057495}{12} t^{4}-\frac{19884341}{12} t^{5}-\frac{5769398299}{72} t^{6}+\frac{400431583141}{504} t^{7}+\cdots \\
& z=37-111 t-\frac{4067}{2} t^{2}+\frac{362101}{6} t^{3}+\frac{861097}{24} t^{4}-\frac{327171397}{40} t^{5}+\frac{4047783797}{80} t^{6}+\frac{326595204709}{560} t^{7}+\cdots
\end{aligned}
$$

The accuracy of the LADM and MLADM is investigated by comparing their solutions to the RK4 solution for the parameter $b=3$ where the system is chaotic with the initial conditions $x(0)=-10, y(0)=0$ and $z(0)=37$. The RK4 with time steps $\Delta t=0.01$ with the number of significant digits set to 16 is used. Table 1 presents the absolute errors between the 21-term LADM solutions and the 21-term MLADM solutions for $b=12$ and the RK4 solutions.

Table 1: Absolute differences between 21-term LADM and 21-term MLADM with RK4 solutions $(\Delta t=0.01)$ for $b=3$.

\begin{tabular}{ccccccc}
\hline \multicolumn{1}{c}{$\left|\mathbf{L A D M}_{\mathbf{0 . 0 1}}-\mathbf{R K 4}_{\mathbf{0 . 0 1}}\right|$} & \multicolumn{3}{c}{$\left|\mathbf{M L A D M}_{\mathbf{0 . 0 1}}-\mathbf{R K 4}_{\mathbf{0 . 0 1}}\right|$} \\
\hline $\boldsymbol{t}$ & $\Delta \boldsymbol{x}$ & $\Delta \boldsymbol{y}$ & $\Delta \boldsymbol{z}$ & $\Delta \boldsymbol{x}$ & $\Delta \boldsymbol{y}$ & $\Delta \boldsymbol{z}$ \\
\hline $\mathbf{0 . 0 2}$ & $2.126 \mathrm{E}-05$ & $1.952 \mathrm{E}-05$ & $2.876 \mathrm{E}-05$ & $2.126 \mathrm{E}-05$ & $1.952 \mathrm{E}-05$ & $2.876 \mathrm{E}-05$ \\
\hline $\mathbf{0 . 4 6}$ & $7.952 \mathrm{E}+14$ & $8.736 \mathrm{E}+14$ & $4.552 \mathrm{E}+15$ & $1.921 \mathrm{E}-06$ & $6.793 \mathrm{E}-07$ & $2.827 \mathrm{E}-06$ \\
\hline $\mathbf{1 . 0 6}$ & $1.476 \mathrm{E}+22$ & $2.469 \mathrm{E}+22$ & $8.264 \mathrm{E}+22$ & $2.864 \mathrm{E}-05$ & $2.630 \mathrm{E}-05$ & $4.409 \mathrm{E}-05$ \\
\hline $\mathbf{2 . 1 1}$ & $1.422 \mathrm{E}+28$ & $2.717 \mathrm{E}+28$ & $7.891 \mathrm{E}+28$ & $3.227 \mathrm{E}-05$ & $1.288 \mathrm{E}-05$ & $1.281 \mathrm{E}-05$ \\
\hline $\mathbf{4 . 0 6}$ & $6.907 \mathrm{E}+33$ & $1.402 \mathrm{E}+34$ & $3.816 \mathrm{E}+34$ & $5.246 \mathrm{E}-05$ & $9.607 \mathrm{E}-05$ & $4.877 \mathrm{E}-05$ \\
\hline $\mathbf{7 . 1 1}$ & $5.090 \mathrm{E}+38$ & $1.062 \mathrm{E}+39$ & $2.807 \mathrm{E}+39$ & $5.422 \mathrm{E}-07$ & $5.432 \mathrm{E}-06$ & $1.155 \mathrm{E}-05$ \\
\hline $\mathbf{1 1 . 3 1}$ & $5.480 \mathrm{E}+42$ & $1.159 \mathrm{E}+43$ & $3.019 \mathrm{E}+43$ & $1.478 \mathrm{E}-06$ & $2.984 \mathrm{E}-08$ & $6.738 \mathrm{E}-06$ \\
\hline $\mathbf{1 6 . 0 6}$ & $6.090 \mathrm{E}+45$ & $1.296 \mathrm{E}+46$ & $3.353 \mathrm{E}+46$ & $2.015 \mathrm{E}-06$ & $7.806 \mathrm{E}-07$ & $2.102 \mathrm{E}-06$ \\
\hline $\mathbf{2 2 . 1 1}$ & $3.644 \mathrm{E}+48$ & $7.788 \mathrm{E}+48$ & $2.005 \mathrm{E}+49$ & $5.079 \mathrm{E}-06$ & $3.835 \mathrm{E}-06$ & $5.295 \mathrm{E}-07$ \\
\hline $\mathbf{2 5 . 6 6}$ & $7.160 \mathrm{E}+49$ & $1.533 \mathrm{E}+50$ & $3.940 \mathrm{E}+50$ & $2.584 \mathrm{E}-06$ & $4.168 \mathrm{E}-06$ & $4.888 \mathrm{E}-06$ \\
\hline $\mathbf{2 9 . 9 6}$ & $1.587 \mathrm{E}+51$ & $3.403 \mathrm{E}+51$ & $8.734 \mathrm{E}+51$ & $7.760 \mathrm{E}-06$ & $9.329 \mathrm{E}-06$ & $5.879 \mathrm{E}-06$ \\
\hline
\end{tabular}


In Table 1, we can observe that the LADM only gives valid result for $t \ll 1$. The MLADM solutions on the time step $\Delta t=0.01$ for the chaotic case agree with the RK4 solutions on the time step $\Delta t=0.01$ to at least 4 decimal places. Hence, for the chaotic Chen system we observe that the MLADM solutions agree with the RK4 solutions to a significant degree. The $x-y, x-z, y-z$ and $x-y-z$ phase portraits for the non-chaotic case obtained using the 21-term MLADM solutions are shown in Fig. 1 to Fig. 4.

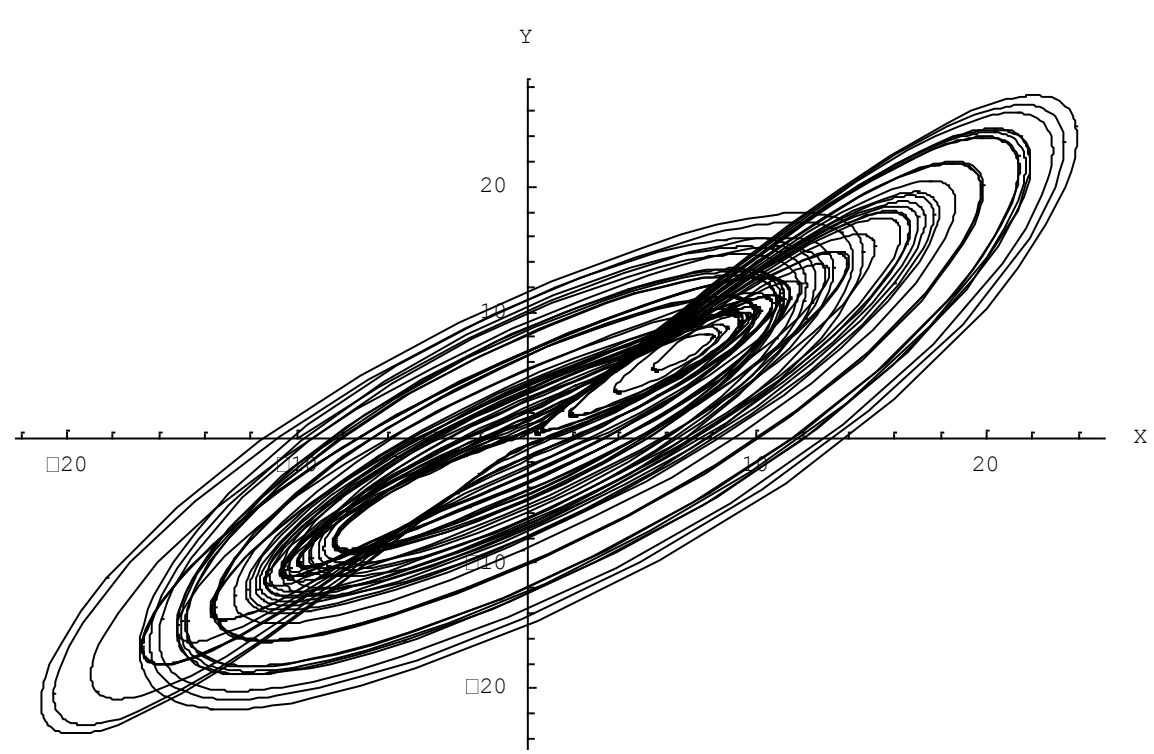

Fig. 1: X-Y Phase portrait using 21-term MLADM on $\Delta t=0.01$ for $b=3$.

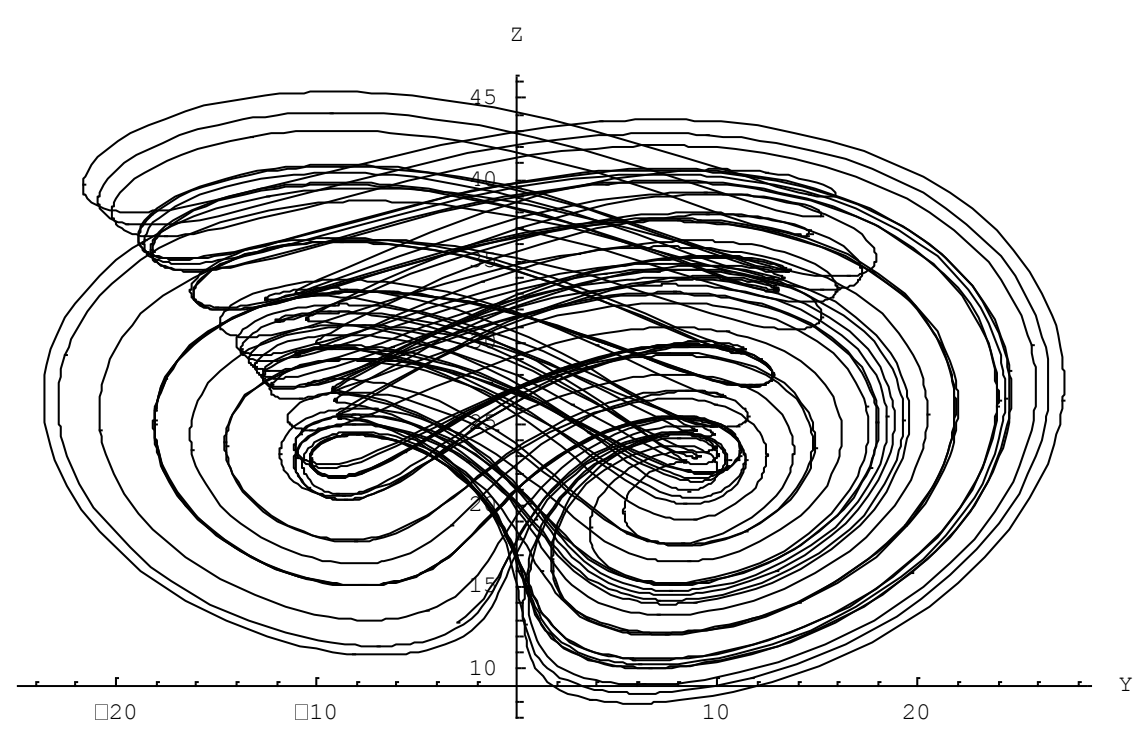

Fig. 2: Y-Z Phase portrait using 21-term MLADM on $\Delta t=0.01$ for $b=3$. 


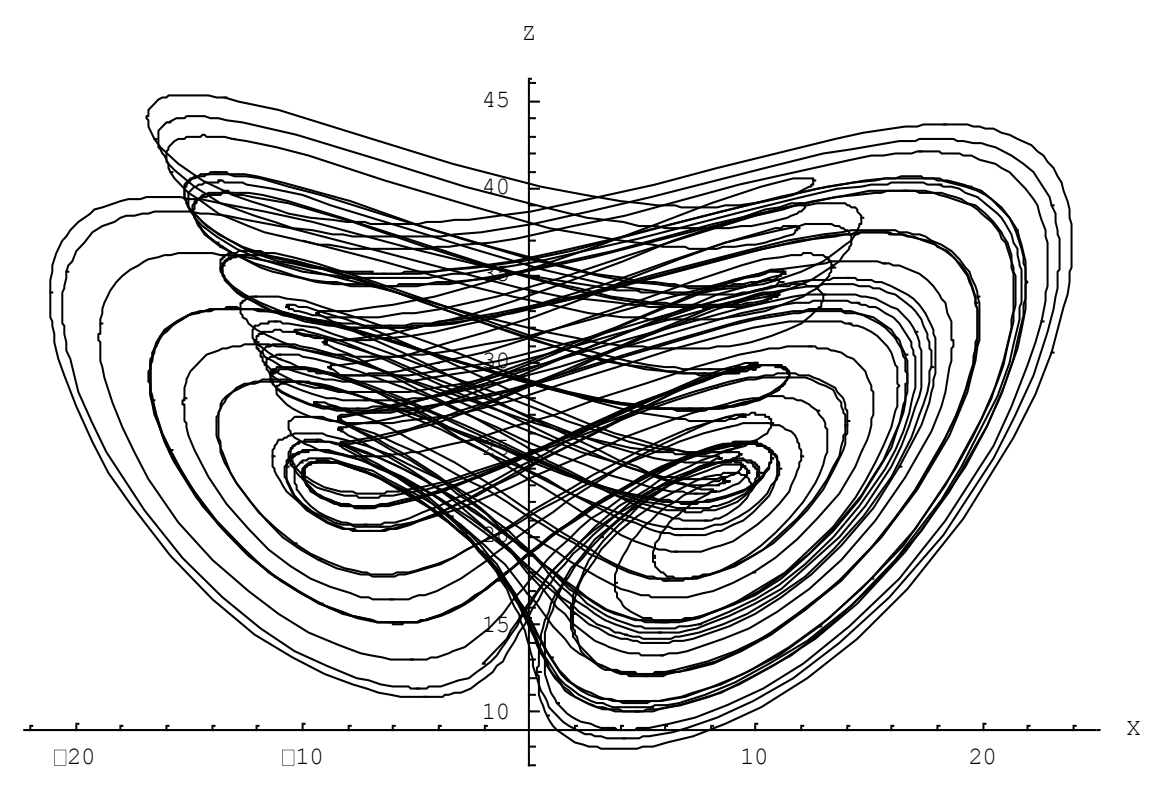

Fig. 3: X-Z Phase portrait using 21-term MLADM on $\Delta t=0.01$ for $b=3$.

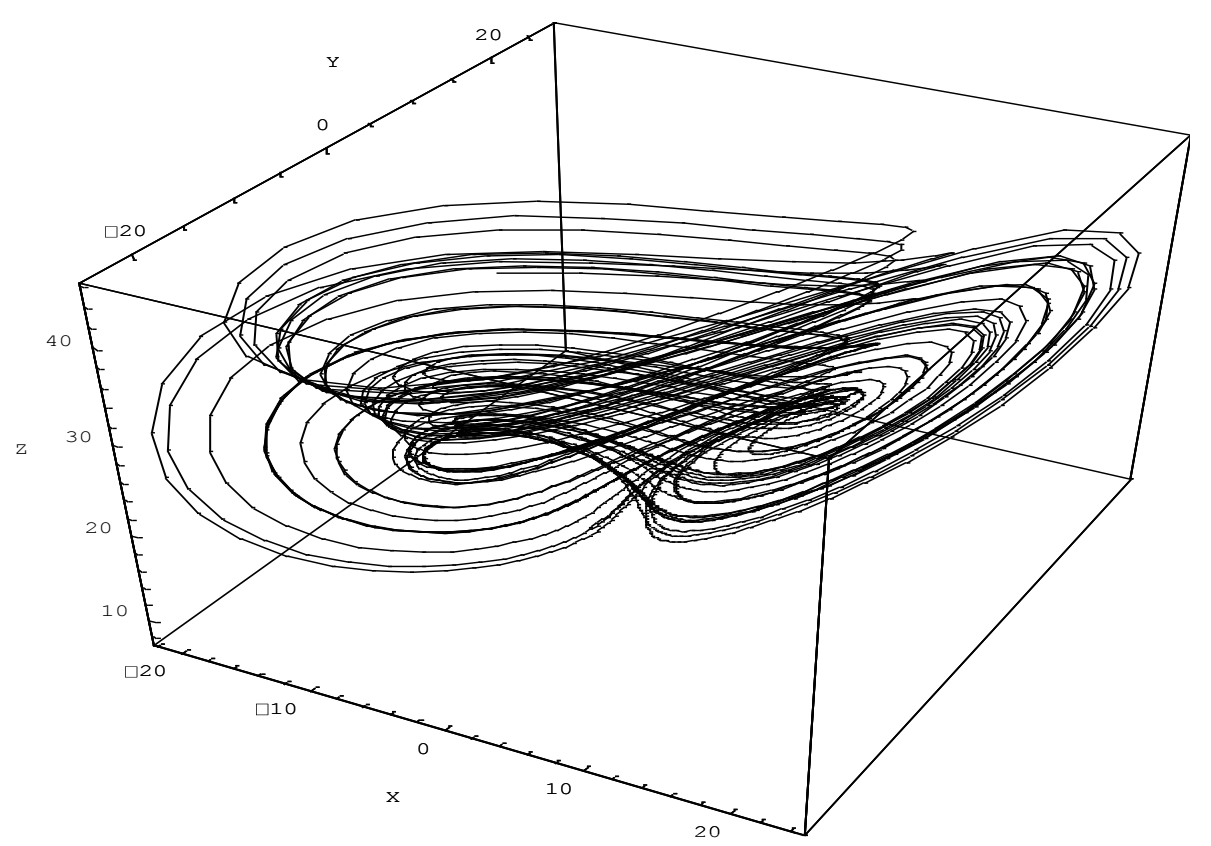

Fig. 4: X-Y-Z Phase portrait using 21-term MLADM on $\Delta t=0.01$ for $b=3$.

The 21 terms approximate LADM solution for the non-chaotic Chen system was obtained as

$x=-10+350 t+1575 t^{2}-\frac{186725}{3} t^{3}+\frac{2008825}{4} t^{4}+\frac{36773275}{12} t^{5}-\frac{1805054335}{24} t^{6}+\frac{13794025585}{72} t^{7}+\cdots$

$y=440 t-3760 t^{2}-\frac{14540}{3} t^{3}+\frac{2819950}{3} t^{4}-\frac{29486417}{3} t^{5}-\frac{332044736}{9} t^{6}+\frac{220205392501}{126} t^{7}+\cdots$

$z=37-444 t+464 t^{2}+\frac{186032}{3} t^{3}-\frac{988996}{3} t^{4}-\frac{40448516}{5} t^{5}+\frac{809770482}{5} t^{6}-\frac{2694568762}{5} t^{7}+\cdots$ 
The differences of the 21-term LADM solutions and 21-term MLADM solutions for $b=12$ and the RK4 solutions with time steps $\Delta t=0.01$ are given in Table 2 .

Table 2: Absolute differences between 21-term LADM and 21-term MLADM with RK4 solutions $(\Delta t=0.01)$ for $b=12$.

\begin{tabular}{ccccccc}
\hline & \multicolumn{3}{c}{$\left|\mathbf{L A D M}_{\mathbf{0 . 0 1}}-\mathbf{R K 4}_{\mathbf{0 . 0 1}}\right|$} & \multicolumn{3}{c}{$\left|\mathbf{M L A D M}_{\mathbf{0 . 0 1}}-\mathbf{R K 4}_{\mathbf{0 . 0 1}}\right|$} \\
\hline $\boldsymbol{t}$ & $\Delta \boldsymbol{x}$ & $\Delta \boldsymbol{y}$ & $\Delta \boldsymbol{z}$ & $\Delta \boldsymbol{x}$ & $\Delta \boldsymbol{y}$ & $\Delta \boldsymbol{z}$ \\
\hline $\mathbf{0 . 0 2}$ & $2.040 \mathrm{E}-04$ & $3.445 \mathrm{E}-04$ & $3.087 \mathrm{E}-04$ & $2.040 \mathrm{E}-04$ & $3.445 \mathrm{E}-04$ & $3.087 \mathrm{E}-04$ \\
\hline $\mathbf{0 . 4 6}$ & $1.763 \mathrm{E}+15$ & $1.567 \mathrm{E}+16$ & $1.672 \mathrm{E}+16$ & $7.047 \mathrm{E}-05$ & $8.276 \mathrm{E}-05$ & $1.434 \mathrm{E}-04$ \\
\hline $\mathbf{1 . 0 6}$ & $3.840 \mathrm{E}+22$ & $2.674 \mathrm{E}+23$ & $3.372 \mathrm{E}+23$ & $5.010 \mathrm{E}-06$ & $3.003 \mathrm{E}-05$ & $1.809 \mathrm{E}-04$ \\
\hline $\mathbf{2 . 1 1}$ & $3.933 \mathrm{E}+28$ & $2.486 \mathrm{E}+29$ & $3.362 \mathrm{E}+29$ & $1.841 \mathrm{E}-04$ & $1.029 \mathrm{E}-04$ & $3.958 \mathrm{E}-05$ \\
\hline $\mathbf{4 . 0 6}$ & $1.968 \mathrm{E}+34$ & $1.186 \mathrm{E}+35$ & $1.661 \mathrm{E}+35$ & $6.400 \mathrm{E}-05$ & $6.501 \mathrm{E}-05$ & $1.346 \mathrm{E}-04$ \\
\hline $\mathbf{7 . 1 1}$ & $1.471 \mathrm{E}+39$ & $8.661 \mathrm{E}+39$ & $1.234 \mathrm{E}+40$ & $2.180 \mathrm{E}-04$ & $3.910 \mathrm{E}-04$ & $3.311 \mathrm{E}-04$ \\
\hline $\mathbf{1 1 . 3 1}$ & $1.594 \mathrm{E}+43$ & $9.286 \mathrm{E}+43$ & $1.334 \mathrm{E}+44$ & $7.006 \mathrm{E}-04$ & $4.654 \mathrm{E}-04$ & $7.007 \mathrm{E}-04$ \\
\hline $\mathbf{1 6 . 0 6}$ & $1.778 \mathrm{E}+46$ & $1.030 \mathrm{E}+47$ & $1.486 \mathrm{E}+47$ & $6.558 \mathrm{E}-04$ & $4.559 \mathrm{E}-04$ & $6.423 \mathrm{E}-04$ \\
\hline $\mathbf{2 2 . 1 1}$ & $1.066 \mathrm{E}+49$ & $6.151 \mathrm{E}+49$ & $8.902 \mathrm{E}+49$ & $3.374 \mathrm{E}-04$ & $2.563 \mathrm{E}-04$ & $2.437 \mathrm{E}-04$ \\
\hline $\mathbf{2 5 . 6 6}$ & $2.097 \mathrm{E}+50$ & $1.208 \mathrm{E}+51$ & $1.750 \mathrm{E}+51$ & $4.314 \mathrm{E}-05$ & $1.586 \mathrm{E}-04$ & $5.787 \mathrm{E}-05$ \\
\hline $\mathbf{2 9 . 9 6}$ & $4.651 \mathrm{E}+51$ & $2.677 \mathrm{E}+52$ & $3.881 \mathrm{E}+52$ & $1.160 \mathrm{E}-04$ & $1.670 \mathrm{E}-05$ & $5.939 \mathrm{E}-05$ \\
\hline
\end{tabular}

In Table 2, we can also observe that the LADM only gives valid result for $t \ll 1$. The MLADM solutions for the nonchaotic case agree with the RK4 solutions to at least 3 decimal places. The $x-y, x-z, y-z$ and $x-y-z$ phase portraits for the non-chaotic Chen system obtained using the 21-term MLADM solutions are shown in Fig. 5 to Fig. 8.

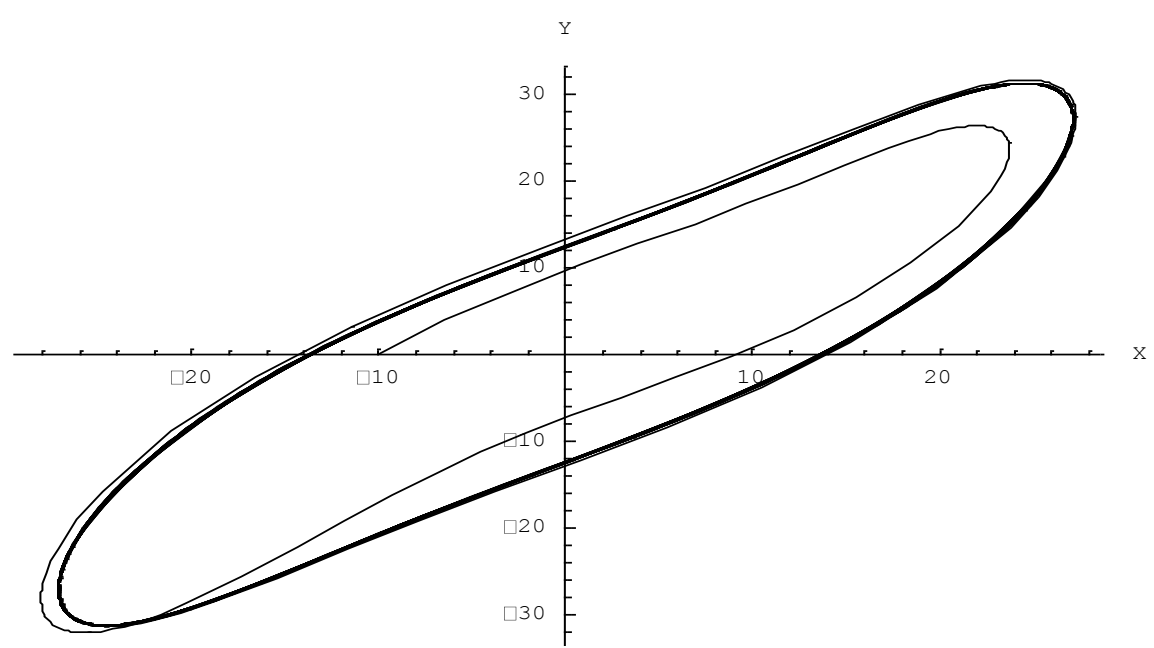

Fig. 5: X-Y Phase portrait using 21-term MLADM on $\Delta t=0.01$ for $b=12$. 


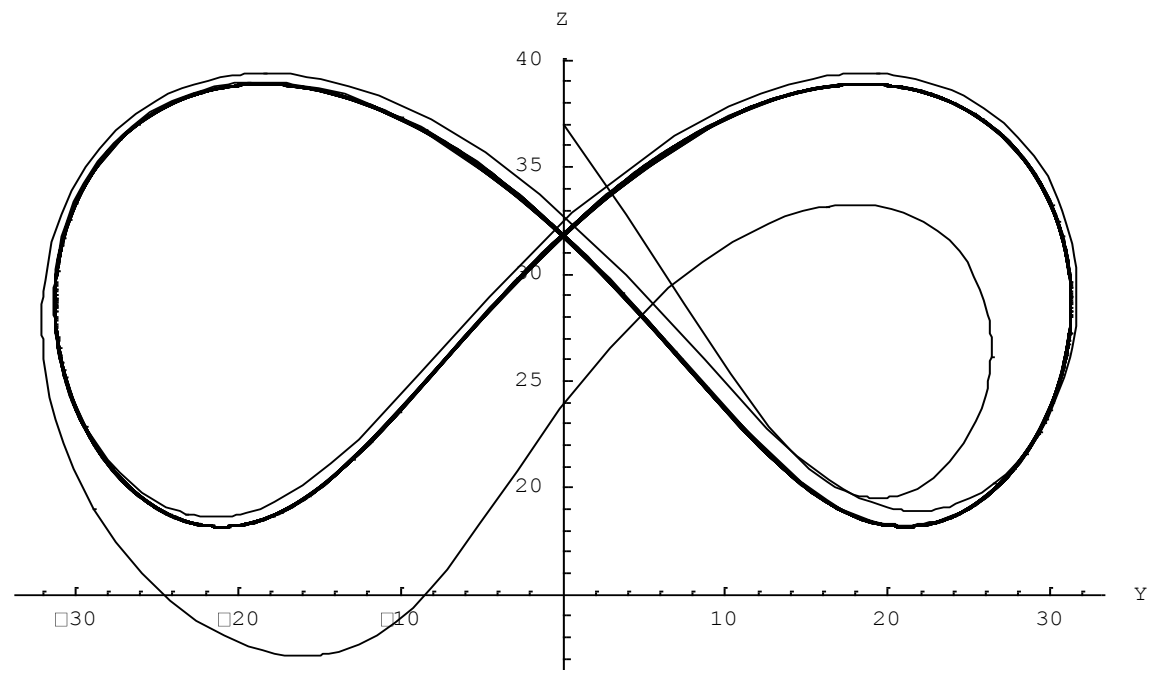

Fig. 6: Y-Z Phase portrait using 21-term MLADM on $\Delta t=0.01$ for $b=12$.

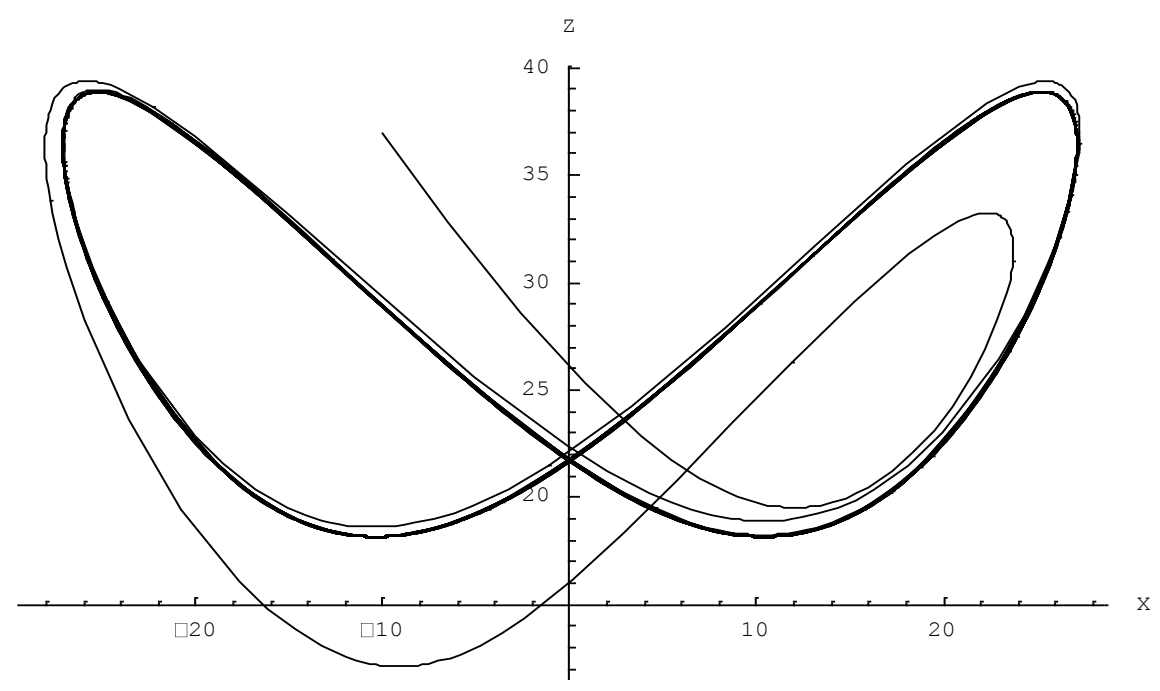

Fig. 7: X-Z Phase portrait using 21-term MLADM on $\Delta t=0.01$ for $b=12$. 


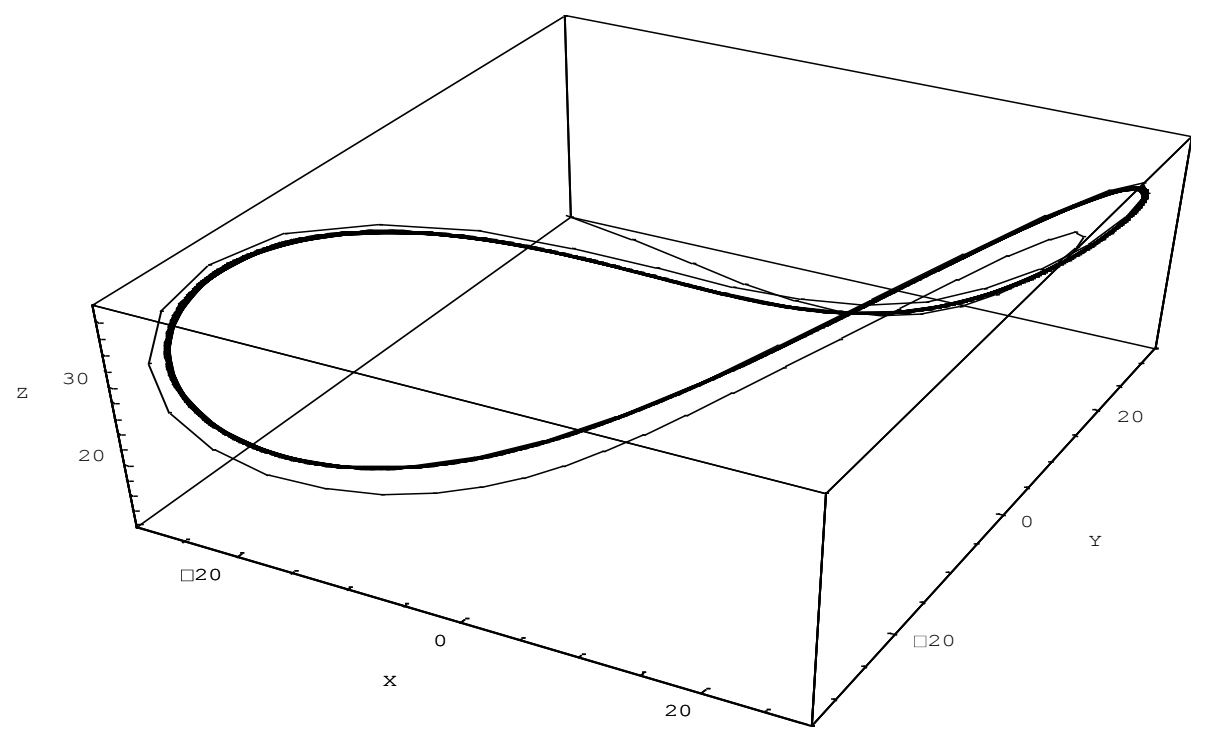

Fig. 8: X-Y Phase portrait using 21-term MLADM on $\Delta t=0.01$ for $b=12$.

\section{Conclusion}

In this work, the LADM and MLADM were applied to the solutions of the Chen system for the chaotic and non-chaotic case. Comparisons were made between the LADM, MLADM and the fourth-order Runge-Kutta (RK4) method. For the chaotic and non-chaotic case, we observe that the MLADM solutions were consistent with the RK4 solutions with MLADM performing better for the chaotic case. Hence, the MLADM is an efficient of solving the Chen system and other nonlinear systems of chaotic nature.

\section{References}

[1] Kyrtsou, C. and Vorlow, C. Complex dynamics in macroeconomics: A novel approach. New Trends in Macroeconomics 2005; $223-238$.

[2] Kyrtsou C. and Labys W. Evidence for chaotic dependence between US inflation and commodity prices. Journal of Macroeconomics 2006; 28: $256-266$.

[3] G. Chen and T. Ueta. Yet another chaotic attractor. International Journal of Bifurcation and Chaos in Applied Sciences and Engineering 1999; 9 (7): $1465-1466$.

[4] T. Ueta and G. Chen. Bifurcation analysis of Chen's equation. International Journal of Bifurcation and Chaos 2000; 10 (8): 1917-1931.

[5] J. Lu, T. Zhou, G. Chen, and S. Zhang. Local bifurcations of the Chen system. International Journal of Bifurcation and Chaos 2002; 12 (10): 2257-2270.

[6] C.P. Li and G.R. Chen. A note one Hopf bifurcation in Chen's system. International Journal of Bifurcation and Chaos 2003; 13(6): 16091615 .

[7] Al-Sawalha M.M and M.S.M. Noorani. On Solving the Lorenz System by Differential Transformation Method. Chin. Phys. Lett. 2008; 25(4): 1217-1219.

[8] M. S. H. Chowdhury and I. Hashim. Application of multistage homotopy-perturbation method for the solutions of the Chen system. Nonlinear Analysis 2009; 10 (1): 381-391.

[9] M. Al-Sawalha and M. Noorani. Application of the differential transformation method for the solution of the hyperchaotic Rossler system. Commun. Nonlin. Sci. Numer. Simulat. 2009; 14 (4): 1509-1514.

[10] Z.M. Odibat, C. Bertelle, M.A. Aziz-Alaoui, and G.H.E. Duchamp. A multi-step diff erential transform method and application to non-chaotic or chaotic systems. Computers \& Mathematics with Applications 2010; 59 (4): 1462-1472.

[11] S.A. Khuri. A Laplace decomposition algorithm applied to class of nonlinear differential equations. J Math. Appl. $2001 ; 4: 141$ - 155.

[12] S.A. Khuri. A new approach to Bratu's problem. Appl. Math. Comput. 2004; 147: 131 - 136.

[13] E. Yusufoglu. Numerical solution of Duffing equation by the Laplace decomposition algorithm. Appl. Math. Comput. 2006; 177: 572 - 580.

[14] S.N. Elgazery. Numerical solution for the Falkner-Skan equation. Chaos, Solitons and Fractals 2008; $35: 738-746$.

[15] M. Hussain and M. Khan. Modified Laplace decomposition method. Appl. Math. Sci. 2010; 4 (36): 1769 - 1783.

[16] Adomian G. Solving Frontier Problems in Physics: The Decomposition Method. Boston: Kluwer Academic Publishers: 1994. 